\title{
Patients' satisfaction and associated factors with nursing care services in selected hospitals, Northwest Ethiopia
}

\author{
Azanu Kibret Negash", ", Wubante Demilew Negussie ${ }^{2}$, Amsalu Feleke Demissie ${ }^{3}$ \\ ${ }^{1}$ Department of Midwifery, College of Health Sciences, Bahir Dar Health Science College, Bahir Dar City \\ ${ }^{2}$ Department of pharmacy, College of Health Sciences, Bahir Dar Health Science College, Bahir Dar City \\ ${ }^{3}$ Department of Health Service Management and Health Economics, College of Medicine and Health Sciences, University of Gondar, \\ Gondar Ethiopia
}

\section{Email address:}

azanukibret97@gmail.com (A. K. Negash),wubdemt@gmail.com (W. D. Negussie), felekeam@yahoo.com (A. F. Demissie).

\section{To cite this article:}

Azanu Kibret Negash, Wubante Demilew Negussie, Amsalu Feleke Demissie. Patients' Satisfaction and Associated Factors with Nursing Care Services in Selected Hospitals, Northwest Ethiopia. American Journal of Nursing Science. Vol. 3, No. 3, 2014, pp. 34-42. doi: 10.11648/j.ajns.20140303.12

\begin{abstract}
Background: Patients satisfaction measures have developed tremendous attractions in the sector of health care delivery services for the purpose of ascertaining the quality of health care services in general and nursing care in particular. It is everyone's most common experience to witness significant patient/ client complaints and dissatisfactions with respect to hospital healthcare deliveries, particularly nursing care services. The objectives of this study was to determine adult patients' satisfaction and associated factors with nursing care at Felege Hiwot Referral and Finote Selam District hospitals, Amhara region, Northwest Ethiopia 2013. Methods: Institutional- based cross-sectional study was conducted from April 1-30, 2013. Systematic random sampling technique was employed and 374 patients were selected from the study wards of the selected hospitals. A 19-items questionnaire, which involved a 5-point Likert scale, was employed to collect the data. Data were collected by trained data collectors using pretested structured questionnaires. Data were checked for completeness, consistency, coded and entered into EPI Info (version 3.5.2) and transferred to SPSS version 16 for analysis. Bivariate and multivariate logistic regression analysis was computed to test the strength of association and level of significance. P-value $<0.05$ was considered as statistical significant. Results: The overall satisfaction was found to be $67.1 \%$. Freedom, privacy given to patients and the capabilities of the nurses at their jobs were the top areas of patients have got satisfied on nursing care services delivered. Patients who were admitted to referral hospital were less likely to be satisfied $(\mathrm{AOR}=0.047$; $\mathrm{CI}: 0.02-0.14)$ than those admitted to district hospital. Patients who earned free hospital services were two times more likely to be satisfied in the overall satisfaction than those who paid for the hospital services $(\mathrm{AOR}=2.01 ; \mathrm{CI}: 1.27-3.48)$ and those patients who were under acute conditions were less likely to report overall satisfaction with nursing care services $(\mathrm{AOR}=0.406$; CI 0.21-0.77) than those under chronic illness. Conclusions: A significant proportion of the study participants $(67.1 \%)$ were satisfied with the overall nursing care services. Differences in the level hospitals where patients admitted to, their ward service type, and their condition of illness were found to be statistically significant predictors of patients' satisfaction. However, the hospitals service needs improvement. The Amhara national regional state (ANRS) Health Bureau is recommended to launch intervention programs to foster the information provision skills and the skills of making clients feel well of the nursing staff at the study hospitals.
\end{abstract}

Keywords: Patients', Satisfaction, Factors, Nursing Care, Ethiopia

\section{Background}

Patient satisfaction measures have developed tremendous attractions in the sector of health care delivery services for the purpose of ascertaining the quality of health care services in general and nursing care in particular. Several authors, in the contemporary health care literature, have indicated that even though patient satisfaction is probably the most difficult to measure among other components in the quality of health care services in general, its importance in determining quality of care cannot be set aside [1].

Among a number of health care services delivered at health institutions, nursing care services constitute the most 
important part, and hence, play the most significant and pivotal role. Regarding this, it was indicated a major service that hospitalized patients are exposed to is nursing care, with nursing personnel comprising the largest proportion of the health service community, and since most of the health care in hospitals is nursing care, it most closely influences the patients' satisfaction with the overall quality of care, and therefore, the importance of measuring patient satisfaction with nursing care cannot be emphasized enough [1]. Also, it was indicated that the increase in consumerism in the health service has focused attention on patients' perceptions of, and satisfaction with, the services they receive, particularly nursing care services [2].

This concern of patients' satisfaction with nursing care has attracted the attention of researchers across the globe. There have been a number of studies conducted on patients' satisfaction with nursing both in the developed nations and developing countries but lack of the studies in Ethiopia [3-5].

The concern of patient satisfaction with nursing care has also attracted the interest of researchers in the Ethiopian context. A study conducted; for example, on adult patient satisfaction with nursing care at public hospitals in Addis Ababa, admitted in the medical, surgical and gynecological wards, depicted that the overall rating of satisfaction was $67 \%$, with the top aspects that patients scored highest for their satisfaction with nursing care were the amount of freedom given, nurses capability in their work and nurses treatment of patients as an individual, and the aspects with which patients were least satisfied were the amount and type of information they received regarding their condition and treatment and also the amount nurses knew about patients' care [6].

It is everyone's most common experience to witness significant patient or client complaints and dissatisfactions with respect to hospital health care deliveries, particularly nursing care services, in many of the Ethiopian healthcare settings [7].

Despite all the aforementioned client disapprovals in the quality of health care services in the Ethiopian settings, a major health care service quality improvement program; namely, the Business Process Re-engineering (BPR) Program, has been designed and put into practice by the ANRS Health Bureau for all the health care component deliveries, including the nursing care services, at the Felege Hiwot Referral Hospital and Finote Selam District Hospital since two and a half years ago. Also, no defined study results on patient satisfaction with particularly nursing care at the indicated hospitals, and at health settings in the neighboring and nearby zones have been accessible to the researcher [8].

Studies on patient satisfaction with nursing care at these particular study settings, and at settings near and neighboring the current study area have not been accessible to the researcher. Hence, one cannot be in a position to ascertain the patients' satisfaction of health care services delivered in the health institutions at these areas.
Consequently, these all things had triggered the researcher to conduct an assessment on patient satisfaction with nursing care at Felege Hiwot Referral and Finote Selam District Hospital, ANRS, Northwest Ethiopia.

Health care providers and more specifically nurses are used as an input to improve nursing care and public relations and also to modify their provision of services in order to make their patients more satisfied. Health care planners, policy makers, and managers can used as benchmarks and comparing patient satisfaction scores with other hospitals, as an input for staff training and implementation of excellence programs in clinical areas, To improve quality of care, planning and evaluation of health care services. Patients/clients themselves are the other most important beneficiaries of the results of this study.

The objectives of this study were to determine adult patients' satisfaction and identify associated factors with nursing care at Felege Hiwot Referral Hospital (FHRH) and Finote Selam District Hospital, ANRS, Northwest Ethiopia.

\section{Methods and Materials}

\subsection{Study Design and Period}

Institution-based cross-sectional study was conducted from April 1-30, 2013 at Felege Hiwot referral hospital and Finote Selam district hospital, Amhara National regional state, Northwest Ethiopia.

\subsection{Study Area}

Felege Hiwot Referral and Finote Selam District hospitals are found some $565 \mathrm{kms}$ and $415 \mathrm{kms}$, respectively away from Addis Ababa, the capital city of Ethiopia, and extend to the North-Western part of the country. They are situated at Bahir Dar city and Finote Selam town, which are the capitals of the ANRS and the West Gojjam Administrative Zones, respectively.

Felege Hiwot Referral Hospital officially commenced its functioning in 1955 E.C. (1963 G.C.), and has currently been delivering its health care services in the medical, surgical, gynecological, pediatrics and ophthalmological wards, and through a total of 324 beds. This hospital is also currently running particularly its nursing care services through a total of 157 medical personnel's; of which 21 of them have hold their B.Sc. in nursing, 117 are clinical nurses (diploma), and 19 are midwives (4 with B.Sc. and 15 with diploma). The hospital has admitted a total of 20,258 patients since the beginning of last year (2004/5 E.C, 14 months). Pannonia, traumas injure fracture, and unspecified obstetrics complications are the three most important morbidity and mortality cases registered at the hospital. The current average patient stay at this hospital is 5.6 days [13].

Similarly, Finote Selam District Hospital was established in 1975 E.C. (1983 G.C.), and has currently been running 
its health care deliveries in the medical, surgical, gynecological, and pediatrics wards, and through a total of 105 beds. This hospital comprises a total of 38 nursing staff; with 3 holding B.Sc. in nursing, 27 earning diploma in clinical nursing and 8 are midwives ( 3 with B.Sc. and 5 with diploma). This hospital has registered a total of 2476 admitted patients since the beginning of last year (2004/5E.C., 14 months). Malaria, helminthes, and Pannonia have been the three top morbidity and mortality cases registered at this hospital the current average patient stay at this hospital is 3.5 days [14].

The Business Process Re-engineering (BPR) Program has been designed and implemented at both these hospitals since two and a half years ago for the purpose of improving the quality, efficiency, and effectiveness of the health care services they deliver.

\subsection{Source Population}

All adult patients who were admitted to Felege Hiwot Referral and Finote Selam District hospitals were the source population.

\subsection{Study Population}

All adult patients who were admitted to the Medical, Surgical, and Gynecology wards of Felege Hiwot Referral and Finote Selam District hospitals during the study period were the study population.

\subsection{Sample Size Determination}

In the study, samples were taken out of the indicated study population. This was determined by considering $67 \%$ level of patient satisfaction with nursing care, at a $95 \%$ confidence level and a 5\% level of statistical significance for accepting a chance of getting a finding that is not actually in the population [6]. A $10 \%$ non-response rate was also considered to determine the final sample size. The final sample size was thus computed as, $n=n=\left(Z_{\alpha / 2}\right)^{2} \mathrm{p}$ (1$\mathrm{p}) / \mathrm{d}^{2}$, Where, $\mathrm{Z}=1.96, \mathrm{~d}=0.05, \mathrm{P}=0.67$, since the level of patient satisfaction with nursing care was known from a previous study done in Addis Ababa, $\mathrm{P}$ was taken as 67\%,

Thus, $\mathrm{n}=\frac{(1.96)^{2}(0.67)(1-0.67)}{(0.05)^{2}}=340$

Finally, considering a $10 \%$ non-response rate, $340+34=$ 374 was the final sample size. Each study hospital contributed its own number of samples proportional to the size it accounted to the total number of beds of both the two hospitals. Thus, Felege Hiwot Referral Hospital contributed about 282(75.52\%) and Finote Selam District Hospital $92(24.47 \%)$ samples to the total sample size, which were 374 .

\subsection{Sampling Procedures}

Through using a systematic random sampling technique, sample patients who stayed in the study wards for at least 2 nights were invited to the survey. Data collection was done to cover Mondays to Sundays. A list of patients for 2 or more night's stay at the wards was obtained once at 10 a.m. (in the morning) and another at around 2 p.m. (in the afternoon). The systematic random sampling technique was conducted in such a way in Felege Hiwot Referral Hospital that first the $5^{\text {th }}$ patient in the list was randomly selected through a lottery method and then every patient in the $5^{\text {th }}$ interval was chosen, the procedure similar to Fenote Selam hospital $2^{\text {nd }}$ interval was chosen until the required number was attained Only those on the list were approached consecutively.

\subsection{Inclusion and Exclusion Criteria}

Patients were included in the survey if they fulfilled the following inclusion criteria of (1) adults, aged 18 years and above; (2) conscious, coherent, and oriented to time, person and place; (3) admitted in the medical, surgical and gynecological wards for at least two days and (4) willing to give informed consent. Those patients' who were too seriously ill and unable to communicate were not included in the study

\subsection{Data Collection Instruments}

This was a modified 19-items instrument employed in this study to determine the selected patients' satisfaction with the nursing care they received during their stay at the study wards in the selected hospitals across various aspects of nursing care services. All the items were scored on a five-point Likert scale ranging from 1 (not at all satisfied) to 5 (completely satisfied). Participants were asked to rate their satisfaction with the various aspects of nursing care by selecting only one number that best describes their opinion on each item of the scale.

The instrument was a standardized tool that was formerly used in a related study conducted in Addis Ababa and modified for use in the current study depending on the various patient satisfactions with nursing care tools used in different studies and presented in the contemporary health care literature.

The responses of 'completely satisfied'/'very satisfied' (5 and 4) were recorded as 'satisfied' (1) and those of 'quite satisfied'/'barely satisfied'/'not at all satisfied' (3,2,and 1) were recorded as 'not satisfied' (0). The proportion of the patients satisfied with the various aspects of nursing care services were then determined in percentages. For determining the overall satisfaction of the participants, their responses of 'completely satisfied'/'very satisfied' (1) to $75 \%$ of the items (at least 14 out of 19) was considered.

The other section of the instrument required the participants to provide information regarding their 15 sociodemographic and patient-related variables. There was also a section in the instrument that involved 4 items and requested the participants to rate their general evaluation of the nursing care they received during their stay at the study wards. 


\subsection{Data Collection Procedures}

The researcher then managed to gather the data through making smooth and cooperative relationships with the concerned bodies in the study wards of the selected hospitals. Three $12^{\text {th }}$ grade completed individuals were recruited and trained to obtain consent and administer the questionnaire privately and maintain confidentiality throughout the process. Since interviews obtain substantially higher response rates that may lessen worry about non-response bias, the questionnaire was administered with interviewer assistance of the trained data collectors. Before the data collectors left the area, all the questionnaires were checked for completeness.

The researcher herself did all the necessary scoring. The items on the instrument were administered to the participants after they were translated into Amharic and later into English by language (translation) professionals. This was done for the purpose of improving the validity of the data. The study participants were asked whether or not they were able to differentiate nursing staff from other health care professionals. If not, the data collectors explained the activities of nursing staffs to the participants, to help them to differentiate the nursing staffs before the interview was conducted. They also instructed about what the items meant and how they could respond to them.

In this study the following words were defined operationally for the purpose of clear understanding.

Nursing staff refers to nurses, junior nurses, midwives who provide nursing care services in the study wards of the selected hospitals.

Satisfied is to mean participants who respond as completely satisfied or very satisfied for satisfaction items.

Not satisfied refers to participants who respond as not at all satisfied, barely satisfied, or quite satisfied for satisfaction items. Generally Satisfied patients: those with responses of satisfied/very satisfied (recoded as 1) to $75 \%$ of the items (at least 14 out of 19) on the questionnaire. Patient-attendant: a relative or family member or friend of a patient who looks after him /her

\subsection{Data Data Quality Assurance}

Before data were collected, the researcher conducted a pre-test for the items on the questionnaire on a sample of 20 patients from Debre Tabour hospital, other than the study's main population. This was done in the middle of March, 2013 and amendments and modifications for the items were made depending on the feedback obtained from the participants. After the data were collected, each questionnaire was checked for completeness, missed values and unlikely responses and then cleaned up. A 19-items questionnaire, which involved a 5-point Likert scale, was employed to collect the data. Data were collected by trained data collectors using pretested structured questionnaires.

The questionnaire was prepared in English and translated into Amharic language and then back to English to keep its consistency. Data collectors were trained for one day. Close supervision was undertaken during data collection and every questionnaire was crosschecked daily by the supervisor and the principal investigator and Problems faced were discussed overnight.

\subsection{Data Management and Analysis}

All the collected data were coded, checked completeness and consistency. Then the data was entered into EPI Info (Epidemiological information. version 3.5.2) and data analysis process was performed using SPSS (Statistical Package for Social Sciences, version 16.0).

Descriptive and bivariate analyses were computed to see the frequency distribution and to test whether there is association between dependent variable and selected independent variables respectively. Factors associated with patient satisfaction at bivariate analysis were identified and the variables with p-value of 0.20 and less were taken to multivariable analysis and the model was built with backward stepwise elimination (backward LR). Finally, the p-values 0.05 and less were considered statistically significant.

\subsection{Ethical Considerations}

Research clearance was primarily obtained from the Regional Ethical Board of ANRS Health Bureau, followed by a request letter for support being obtained from Bahir Dar University. The study subjects were requested to give their consent after receiving adequate explanation about the purpose, type of questions, and how they could give their responses. They were also told about the significance, and the anonymity of the informants, their rights to withdraw from the study, and not to answer questions whenever they felt uncomfortable. All the study participants were informed about the purpose of the study, their right to refuse and assurance of confidentiality. Oral informed verbal consent was obtained from every respondent. Strict confidentiality was assured through anonymous recording and coding of questionnaire

\section{Results}

\subsection{Socio-Demographic and Admission Characteristics of Respondents and Other Patient-Related Factors}

A total of 374 participants took part in the study, of which 373 gave responses to the survey items completely, but one interviewee didn't answer to the main component of questions and was excluded from analysis, a response rate of $373(99.7 \%)$. According to the finding of this study, $187(50.1 \%)$ were females and 201(53.9\%) were from rural residence. Considerable number of the participants $181(48.5 \%)$ had no formal education and $271(72.7 \%)$ respondents were married whereas $182(48.8 \%)$ of the participants were farmers. On the other hand, 179 (48.0\%) of the participants were in the age group of 18-30 years, with their mean age of $35.6(\mathrm{SD}=13.6)$, while $178(47.7 \%)$ of them 
earn 151-600 ETB a month, with their mean monthly earning being 945.00 Ethiopian Birr ( $\mathrm{SD} \pm 830.7)$ (Table 1).

Regarding the patient related characteristics, more than one third of the participants $131(35.2 \%)$ received the services free of charge. Concerning the participants' history of admission at the study hospitals, 298 (79.9\%) of them were not previously admitted, while a significant number of them, 309 (82.8\%) were under acute illness conditions. The patient-attendant relationship, $130 \quad(34.9 \%)$ of the participants were being given care by their relatives other than parent, child or spouse during their stay at the study wards of the selected hospitals. 137 (36.7\%) were admitted at the medical wards of the study hospitals and 281 (75.3\%) were from Felege Hiwot Referral Hospital.

Lastly, 284(76.1\%) of the participants stayed in the study hospitals for 2-7 night, with the mean length of stays (nights) 6.9 ( $\mathrm{SD} \pm 7.1$ ), while $259(71 \%)$ of them stayed with their attendants for 19-24 hours, with the mean number of hours being $19.5(\mathrm{SD} \pm 7.2)$ (Table 2).

Table 1. Socio-demographic Characteristics of Respondents in selected Hospitals, ANRS, Northwest Ethiopia, April 1-30, 2013 (n=373)

\begin{tabular}{|c|c|c|}
\hline Respondents' Characteristics & $\mathbf{n}$ & $\%$ \\
\hline \multicolumn{3}{|l|}{ Sex } \\
\hline Male & 186 & 49.9 \\
\hline Female & 187 & 50.1 \\
\hline \multicolumn{3}{|l|}{ Age } \\
\hline Mean (SD) & 35.6 & $( \pm 13.6)$ \\
\hline $18-30 \mathrm{yrs}$ & 179 & 48.0 \\
\hline $31-40$ yrs & 100 & 26.8 \\
\hline $41-50 \mathrm{yrs}$ & 41 & 11.0 \\
\hline $51-60 \mathrm{yrs}$ & 26 & 7.0 \\
\hline$\geq 61 \mathrm{yrs}$ & 27 & 7.2 \\
\hline \multicolumn{3}{|l|}{ Income } \\
\hline (In ETB) Mean (SD) & 945.40 & $( \pm 830.7)$ \\
\hline$\leq 150$ birr & 7 & 1.9 \\
\hline $151-600$ birr & 178 & 47.7 \\
\hline $601-1200$ birr & 104 & 27.9 \\
\hline $1201-2500$ birr & 69 & 18.5 \\
\hline$\geq 2501$ birr & 15 & 4.0 \\
\hline \multicolumn{3}{|l|}{ Residence } \\
\hline Rural & 201 & 53.9 \\
\hline Urban & 172 & 46.1 \\
\hline \multicolumn{3}{|l|}{ Educational status } \\
\hline No formal education & 181 & 48.5 \\
\hline Primary school & 82 & 22 \\
\hline Secondary School & 53 & 14.2 \\
\hline College Diploma and above & 57 & 15.3 \\
\hline \multicolumn{3}{|l|}{ Occupation } \\
\hline Daily laborer & 31 & 8.3 \\
\hline Government employee & 55 & 14.7 \\
\hline NGO employee & 4 & 1 \\
\hline Farmer & 182 & 48.8 \\
\hline Private employee & 67 & 17.9 \\
\hline House wife & 22 & 5.9 \\
\hline Others & 12 & 3.2 \\
\hline \multicolumn{3}{|l|}{ Marital Status } \\
\hline Married & 271 & 72.7 \\
\hline Unmarried & 70 & 18.8 \\
\hline Divorced & 15 & 4.0 \\
\hline Widowed & 17 & 4.6 \\
\hline
\end{tabular}

Table 2. Patient-related (admission-related) Characteristics of the Participants, in selected Hospitals, ANRS, Northwest Ethiopia, April 1 30, $2013(n=373)$

\begin{tabular}{|c|c|c|}
\hline Respondents' Characteristics & $\mathbf{n}$ & $\%$ \\
\hline $\begin{array}{l}\text { Number of days (nights) stayed in } \\
\text { hospital } \Rightarrow \text { Mean (SD) }\end{array}$ & 6.9 & $( \pm 7.1)$ \\
\hline $2-7$ & 284 & 76.1 \\
\hline $8-15$ & 65 & 17.4 \\
\hline $16-30$ & 20 & 5.4 \\
\hline $31-60$ & 3 & 0.8 \\
\hline$>61$ & 1 & 0.3 \\
\hline \multicolumn{3}{|l|}{ Ward Service Type } \\
\hline Free & 131 & 35.1 \\
\hline Payment & 242 & 64.9 \\
\hline \multicolumn{3}{|l|}{ History of admission } \\
\hline Yes & 75 & 20.1 \\
\hline No & 298 & 79.9 \\
\hline \multicolumn{3}{|l|}{ Medical Conditions } \\
\hline Acute Illness/Conditions & 309 & 82.8 \\
\hline Chronic Illness/conditions & 64 & 17.2 \\
\hline $\begin{array}{l}\text { Number of Hours Spent with patient } \\
\text { attendant } \Rightarrow \text { Mean (SD) }\end{array}$ & 19.5 & $( \pm 7.2)$ \\
\hline $1-6$ & 26 & 7.1 \\
\hline $7-12$ & 77 & 21.1 \\
\hline $13-18$ & 3 & 0.8 \\
\hline $19-24$ & 259 & 71 \\
\hline \multicolumn{3}{|l|}{ Attendant Relationship with Patient } \\
\hline Parent & 72 & 19.3 \\
\hline Child & 69 & 18.5 \\
\hline Relatives & 130 & 34.9 \\
\hline Unrelated & 8 & 2.1 \\
\hline Spouse & 80 & 21.4 \\
\hline Others & 14 & 3.8 \\
\hline \multicolumn{3}{|l|}{ Admission Ward } \\
\hline Medical & 137 & 36.7 \\
\hline Surgical & 134 & 35.9 \\
\hline Gynecological & 102 & 27.3 \\
\hline \multicolumn{3}{|l|}{ Admission Hospital } \\
\hline Felege Hiwot & 281 & 75.3 \\
\hline Finote Selam & 92 & 24.7 \\
\hline
\end{tabular}

\subsection{Patients' Satisfaction with Nursing Care Scores}

The results of this study revealed that $67.1 \%$ of the study participants were satisfied with the overall nursing care services. The number of respondents who have got freedom $310(83.1 \%)$, privacy given $302(81.0 \%)$ and capability of nurses at their job $299(80.2 \%)$ were the three aspects of nursing care services which were satisfied with the highest proportion of the study participants. On the contrary, the amount and type of information given to patients about their condition and treatment were $227(60.9 \%), 243(65.1 \%)$ respectively. The way how nurses made the patients feel as home during their stay at the wards, the way nurses explained things to patient and the way how nurses put the minds of the patients' relatives/friends at rest regarding their conditions were 252 (67.6\%), $260(69.7 \%)$ and $260(69.7 \%)$ respectively which relatively found to be the least satisfaction proportions.

On the other hand, nurses checked often to see the patients well were $(29.0 \%)$, nurses came quickly when the patients called for them $(27.6 \%)$, the availability of a nurse around when patients needed (27.1\%), nurses' awareness of patients' needs $(26.8 \%)$, nurses helpfulness $(26.0 \%)$, nurses 
listened to patients' worries and concerns $(25.7 \%)$, and the amount nurses knew about patients' care (25.5\%) were nursing care services with which a considerable proportion of the study participants were dissatisfied (Table 3).

Table 3. Frequency of Satisfied/Not Satisfied Patients with the Different Aspects of Nursing Care Services in selected Hospitals, ANRS, Northwest Ethiopia, April 1 - 30, $2013(n=373)$

\begin{tabular}{|c|c|c|c|}
\hline The Items & $\begin{array}{l}\text { S } \\
\text { No }(\%) \\
\end{array}$ & $\begin{array}{l}\text { NS } \\
\text { No }(\%)\end{array}$ & $\begin{array}{l}\text { T } \\
\text { No (\%) }\end{array}$ \\
\hline 1. The amount of time nurses spent & $292(78.3)$ & $81(21.7)$ & $373(100)$ \\
\hline 2. How capable nurses were at their job & $299(80.2)$ & $74(19.8)$ & $373(100)$ \\
\hline 3. There always being a nurse around when needed & $272(72.9)$ & $101(27.1)$ & $373(100)$ \\
\hline 4. The amount nurses knew about your care & $278(74.5)$ & $95(25.5)$ & $373(100)$ \\
\hline 5. How quickly nurses came when you called for them & $270(72.4)$ & $103(27.6)$ & $373(100)$ \\
\hline 6. The way the nurses made you feel at home & $252(67.6)$ & $121(32.4)$ & $373(100)$ \\
\hline 7. The amount of information nurses gave to you about your condition and treatment & $227(60.9)$ & $146(39.1)$ & $373(100)$ \\
\hline 8. How often nurses checked to see if you were well & $265(71.0)$ & $108(29.0)$ & $373(100)$ \\
\hline 9. Nurses' helpfulness & $276(74.0)$ & $97(26.0)$ & $373(100)$ \\
\hline 10. The way nurses explained things to you & $260(69.7)$ & $113(30.3)$ & $373(100)$ \\
\hline 11. How nurses helped put your relatives' or friends' minds at rest & $260(69.7)$ & $113(30.3)$ & $373(100)$ \\
\hline 12. Nurses' manner in going about their work & $284(76.1)$ & $89(23.9)$ & $373(100)$ \\
\hline 13. The type of information nurses gave to you about your condition and treatment & $243(65.1)$ & $130(34.9)$ & $373(100)$ \\
\hline 14. Nurses' treatment of you as an individual & $294(78.8)$ & $79(21.2)$ & $373(100)$ \\
\hline 15. How nurses listened to your worries and concerns & $277(74.3)$ & $96(25.7)$ & $373(100)$ \\
\hline 16. The amount of freedom you were given on the ward & $310(83.1)$ & $63(16.9)$ & $373(100)$ \\
\hline 17. How willing nurses were to respond to your requests & $286(76.7)$ & $87(23.3)$ & $373(100)$ \\
\hline 18. The amount of privacy nurses gave you & $302(81.0)$ & $71(19.0)$ & $373(100)$ \\
\hline 19. Nurses' awareness of your needs & $273(73.2)$ & $100(26.8)$ & $373(100)$ \\
\hline
\end{tabular}

$\mathrm{S}=$ satisfied, $\mathrm{NS}=$ not satisfied, $\mathrm{T}=$ total

Finally, the opinions of study participants on the general nursing care they received during their stay at the wards met their expectations were 301 (80.7\%), while 305 $(81.8 \%)$ of the participants were overall satisfied with the nursing care services they received at the study hospitals.
Hence, $332(89.0 \%)$ of the participants were recommend their family and friends to visit the hospitals they stayed and $331(88.7 \%)$ participants want to sick again and need hospitalization (Table 4).

Table 4. The Participants' Responses on the General Opinions of the Nursing Care Services rendrered at the study wards of Felege Hiwot Referral and Finote Selam District Hospitals, ANRS, Northwest Ethiopia, April 1-30, 2013.

\begin{tabular}{|c|c|c|c|}
\hline \multirow[b]{2}{*}{ No. } & \multirow[b]{2}{*}{ The General Opinions } & \multicolumn{2}{|l|}{ The response Options } \\
\hline & & Strongly Agree/Agree & $\begin{array}{l}\text { Uncertain/Disagree/Str } \\
\text { ongly Disagree }\end{array}$ \\
\hline 1 & Overall, the nursing care I received met my expectations & $301(80.7 \%)$ & $72(19.3 \%)$ \\
\hline 2 & Overall, I am satisfied with the nursing care services I received at this hospital & $305(81.8 \%)$ & $68(18.2 \%)$ \\
\hline 3 & I will recommend this hospital to my family and friends. & $332(89.0 \%)$ & $41(11.0 \%)$ \\
\hline 4 & If I get sick again and need hospitalization, I want to come back to this hospital & $331(88.7 \%)$ & $42(11.3 \%)$ \\
\hline
\end{tabular}

\subsection{Regression Analysis on Patients' Satisfaction with Nursing Care and Selected Variables}

Among a number of socio-demographic and patientrelated factors included in this study, only few were identified as significant predictors of the patients' overall satisfaction with nursing care services in the multivariate analysis. These include the level of hospitals patients were admitted, ward service type and their conditions of illness were found to be statistically significant predictors of patients' satisfaction. Those patients who were admitted in
Felege Hiwot hospital were less likely to be satisfied $(\mathrm{AOR}=0.047,95 \% \mathrm{CI}: 0.017-0.135)$ compared to those admitted in Finote Selam hospital. Patients who earned free hospital services were two times more likely to be satisfied in the overall services than those who paid for the hospital services $(\mathrm{AOR}=2.10, \mathrm{CI}$ : 1.27-3.48). Finally, those patients who were under acute conditions were less likely to report overall satisfaction with nursing care services (AOR= 0.406, 95\% CI: $0.214-0.771$ ) than those under chronic illness conditions (Table 5) 
Table 5. Comparison of Participants' Overall Satisfaction with Nursing Care Services Rendered in selected Hospitals, ANRS, Northwest Ethiopia from April 1-30, 2013.

\begin{tabular}{|c|c|c|c|c|}
\hline \multirow{2}{*}{ Variables } & \multicolumn{4}{|c|}{ Patients satisfaction } \\
\hline & Satisfied \% (No) & Not Satisfied \% (No) & COR $(95 \%$ CI) & AOR (95 \% CI) \\
\hline \multicolumn{5}{|l|}{ Hospital level } \\
\hline Referral(Felege Hiwot) & $58(163)$ & $42(118)$ & $0.062(0.042-0.727)$ & $0.047(0.017-0.135)^{*}$ \\
\hline District (Finote Selam) & $96(88)$ & $4(4)$ & 1.00 & 1.00 \\
\hline \multicolumn{5}{|l|}{ Ward Service Type } \\
\hline Free & $73(96)$ & $27(35)$ & $1.539(1.343-2.406)$ & $2.101(1.269-3.481)$ * \\
\hline Payment & $64(155)$ & $36(87)$ & 1.00 & 1.00 \\
\hline \multicolumn{5}{|l|}{ Condition of Illness } \\
\hline Acute & $65(201)$ & $35(108)$ & $0.620(0.341-0.861)$ & $0.406(0.214-0.771)^{*}$ \\
\hline Chronic & $75(48)$ & $25(16)$ & 1.00 & 1.00 \\
\hline \multicolumn{5}{|l|}{ Residence } \\
\hline Rural & $63(127)$ & $37(74)$ & $0.664(0.441-0.957)$ & $0.69(0.42-1.12)$ \\
\hline Urban & $72(124)$ & $28(48)$ & 1.00 & 1.00 \\
\hline \multicolumn{5}{|l|}{ Marital Status } \\
\hline Divorced & $73(11)$ & $27(4)$ & $1.494(1.329-6.833)$ & $2.32(0.44-12.19)$ \\
\hline Married & 69 (187) & $31(84)$ & $1.267(1.085-3.393)$ & $1.84(0.57-5.94)$ \\
\hline Unmarried & $59(41)$ & $41(29)$ & $0.767(0.382-0.927)$ & $1.02(0.28-3.66)$ \\
\hline Widowed & $65(11)$ & $35(6)$ & 1.00 & 1.00 \\
\hline \multicolumn{5}{|l|}{ Ward } \\
\hline Gynecological & $71(72)$ & $29(30)$ & $1.340(1.231-3.329)$ & $1.4990 .75-2.95)$ \\
\hline Medical & $67(92)$ & $33(45)$ & $1.141(1.037-4.152)$ & $1.33(0.75-2.36)$ \\
\hline Surgical & $64(86)$ & $36(48)$ & 1.00 & 1.00 \\
\hline
\end{tabular}

Note: * statistically significant at $\mathrm{P}<0.05$

\section{Discussions}

The finding of this study revealed that the overall satisfaction level of the patients with the nursing care services rendered at Felege Hiwot Referral and Finote Selam District Hospitals was $67.1 \%$. This was almost similar to a study done on adult patients from medical, surgical and gynecological wards in three government hospitals in Addis Ababa, which reported that the overall rating of satisfaction was $67 \%$ [6]. However, it could be considered to be lower as compared to studies conducted on client satisfaction with utilization of primary health care services delivered by a nurse practitioner in the Employee Health Services department of a not for profit hospital, in the Southern United States, revealed that overall high levels of patient satisfaction with nurse practitioner delivered health care services were demonstrated, with the mean general satisfaction score determined to be $86.86 \%$ [4]. Also, the findings of a study conducted on patients hospitalized with cancer in Tehran teaching hospitals, Iran, revealed that a vast majority of these respondents $(82.8 \%)$ were satisfied with the nursing care provided to them [11].

The result of the overall satisfaction of this study was found to be higher than a study conducted on patients admitted in the medical wards of the UP-PGH (Philippino General Hospital), Philippines, depicted that over half $(57.8 \%)$ of the respondents were highly satisfied in the overall evaluation of care [1]. Contrasting results were reported by studies undertaken within the context of African countries. A study conducted on patients drawn from all admission wards in the University of Benin Teaching Hospital, revealed a need for improvement provision of information, explanations of procedures and investigations to patients [5]. This information gap was also identified in the current study and needs improvement in the provision of information to patients.

A study done on quality of nursing care in Federal tertiary hospitals, at Enugu, Southeast Nigeria, showed that patients were satisfied with physical and psychological care, satisfaction was marginal, as nurses seemed to lack skills to meet the needs of patients, and patients' satisfaction with nurses attitude was marginally positive. The study also showed that there was a need for improvement in the nursing care provision for patients in dimension [12].

In this study, comparatively lower overall satisfaction level of patients with the nursing care services rendered could be due to the fact that there had been a considerable level of differences between the Ethiopian health facilities and nursing care service quality and the more developed countries. However, the opinions of study participants on the general nursing care they received during their stay at the wards met their expectations were $301(80.7 \%)$, while $305(81.8 \%)$ of the participants were overall satisfied with the nursing care services they received at the study hospitals. Hence, $332(89.0 \%)$ of the participants were recommend their family and friends to visit the hospitals they stayed and $331(88.7 \%)$ participants want to sick again and need hospitalization which was higher than a study conducted in Philippines general hospital revealed that $34.3 \%$ and $35 \%$ of them were highly satisfied with their experience regarding the nurses' care attitude and the nurses' skill /competence respectively [1]. From these, one can learn that even though the overall satisfaction proportion was $67.1 \%$, the majority of the participants in this study were over all satisfied with the nursing care services they received at the study wards. 
The number of respondents who have got freedom 310 $(83.1 \%)$, privacy given $302(81.0 \%)$ and capability of nurses at their job $299(80.2 \%)$ were the three aspects of nursing care services which were satisfied with the highest proportion of the study participants. On the contrary, the amount and type of information given to patients about their condition and treatment were $(60.9 \%)$ and $(65.1 \%)$ respectively. The way how nurses made the patients feel as home during their stay at the wards, the way nurses explained things to patient and the way how nurses put the minds of the patients' relatives/friends at rest regarding their conditions were $(67.6 \%),(69.7 \%)$ and $(69.7 \%)$ respectively which relatively found to be the least satisfaction proportions which was higher than a study conducted in Philippines general hospital [1].

On the other hand, it is surprising that the amount and type of information nurses gave to patients about their condition and treatment, the way how nurses made the patients feel at home during their stay at the wards, the way nurses explained things to patients, and the way how nurses put the minds of the patients' relatives and friends at rest regarding their conditions were the least satisfaction proportions. Hence, the information provision and the communication skills of the nursing staff at the study hospitals were found to be weaker. This could be because of either the nurses' reluctance to exhibit these important qualities of providing care, or their ignorance of the skills altogether. Also, the nursing staffs were found to be weaker in terms of their skills of making patients feel as home, and putting the minds of their relatives and friends at rest. Therefore, this could also be due to the reasons indicated above and these were the most overlooked areas of caring services delivered at the study hospitals.

Concerning the socio-demographic and patient-related characteristics of the participants predicting their overall satisfaction, differences in the ward service type (Free/Payment), the level of hospitals at which the participants served, and the patients' condition of illness were found to be statistically associated with the participants' overall satisfaction with nursing care services. Contrary to this, a similar study conducted on adult patients from medical, surgical and gynecological wards in three government hospitals in Addis Ababa, reported that age, gender, educational status, and monthly income were significant predictors of patients' overall satisfaction with nursing care services $(p<0.05)$ [6]. However, a study conducted on client satisfaction with utilization of primary health care services delivered by nurses practitioner in the Southern United States, revealed that no statistically significant differences in between gender, race, age, educational level completed, type of health care coverage, yearly net income levels, patient type, employment status, or degree of illness or injury [4].

In the current study, those patients who were admitted to Felege Hiwot hospital were less likely to be satisfied $(\mathrm{AOR}=0.047,95 \% \mathrm{CI}: 0.017-0.135)$ than those admitted to
Finote Selam hospital (Table 5). This could be due to the fact that Felege Hiwot hospital is a referral hospital in the region which is admitting by far greater patient flow, which could hamper the qualities of the healthcare deliveries in general, and the nursing care services in particular. On the other hand, in this study, patients who earned free hospital services $(\mathrm{AOR}=2.101,95 \% \mathrm{CI}: 1.269-3.481)$ were more likely satisfied compared to those who paid for the services. This could indicate that the patients who earned the free hospital services rendered enjoyed the nursing care services whereas patients who paid for the services did not meet their expectations.

Finally, the current study also revealed that those patients who were under acute illness conditions were less likely to report overall satisfaction with nursing care services $(\mathrm{AOR}=$ 0.406, 95\% CI: $0.214-0.771)$ than those under chronic conditions. This could be due to the fact that the chronic patients had already been accustomed to the dissatisfying hospital conditions and became less sensitive to them.

\section{Limitations of the Study}

As to the limitation of this study, it could have been better to conduct certain in-depth interviews or focus group discussions among the patients for further qualitative exploration of the case to back the quantitative data. However, time and logistic constraining factors prevented the researcher from doing so.

\section{Conclusions}

A good proportion of the study participants were satisfied with the overall nursing care services; however, considerable proportions were not satisfied.

The amount of freedom and privacy given to patients in the wards by nurses, and the capabilities of nurses at their job were the three aspects of nursing care services with the strongest quality of healthcare services that should be sustained and improved more. On the contrary, the information provision and communication skills and the skills of making clients feel well of the nursing staff at the study hospitals were found to be weaker.

Differences in the ward service type (Free/Payment), the level of hospitals at which the participants served, and the patients' condition of illness were found to be statistically associated with the participants' overall satisfaction with nursing care services. The concerned bodies at the administrative positions of the study hospitals or higher organizational hierarchies at the ANRS Health Bureau are recommended to design and launch intervention programs to improve the information provision and communication skills and the skills of making clients feel well of the nursing staff at the study hospitals. Improve the nursing care services rendered at hospitals by devising more suitable organization and scale up nursing care services for free of charge, or set costs at minimum to meet clients' expectations. 


\section{Competing Interests}

The authors declare that there is no any competing interests.

\section{Authors' Contribution}

AK: Conceptualized the research problem, designed the study, prepared the proposal, conducted field work, analyzed the data and prepared the report.AF: Revised the proposal and report WD: Revised the proposal and report, prepare the manuscript for publication.

\section{Acknowledgements}

Our great thanks go to Amhara National Regional State Health Bureau and each study hospital's planning and program administrative bodies for their cooperation in providing the information required for the study. We would like to express our grateful heartfelt appreciation to Felege Hiwot Referral Hospital and Finot Selam district hospital administrators, technical staffs and supervisors of the study for their cooperation and support, giving unreserved time and follow up from the beginning till completion of this research thesis.

Our acknowledgement also extends to study participants and data collectors who were involved in this study.

Last but not least, we would like to forward our heartfelt thanks to Ato Wulual Fikrie and Ato Destaw kibret whose support were source of especial strength towards the success to completion.

\section{References}

[1] Maria Vanessa C, Villarruz-Sulit, Antonio L, Dans and Mark Anthony U, and Javelosa. Measuring Satisfaction with Nursing Care of Patients Admitted in the Medical Wards of the Philippine General Hospital. Section of Adult Medicine and Medical Research Unit, Department of Medicine, Philippine General Hospital. 2009; 43 (4):52-55.

[2] Haslock I. Quality of Care and Patient Satisfaction. British Journal of Rheumatology, 1996; 35:382-384.

[3] Kulkarni M V, Dasgupta S, Deoke A R. Study of Satisfaction of Patients Admitted in a Teritiary Care Hospital in Nagpur. National Journal of Community Medicine, 2011; 2 (1):38-39

[4] Lucie AJ. Patient Satisfaction with Nurse Practitioner Delivered Primary Health Care Services. Houston: Louisiana State University; 1983; 47-55.

[5] Ofovwe CE, Ofili AN. Indices of patient satisfaction in an African population. Journal of Public Health, 2005; 119 (7):582-6

[6] Chaka B. Adult Patient Satisfaction with Nursing Care: Addis Ababa University; 2005; 24-34.
[7] Gill L, White L. A critical review of patient satisfaction. Leadership in Health Services, 2009; 22(1): 8-19.

[8] Chawani FS. Patient Satisfaction with Nursing Care: A Meta Synthesis. Johannesburg: University of the Witwafersrand; 2009;55-57.

[9] Kumari R, Idris MZ, Bhushan V, Shanna A, Agarwal M, and Singh SK. Study on Patient Satisfaction in the Government Allopathic Health Facilities of Lucknow District, India. Indian Journal of Community Medicine, 2009; 34 (1):37-40.

[10] Ehiemere IO, Ada N, Peace I, and Akpati V. Helpless patients' satisfaction with quality of nursing care in Federal tertiary hospitals, Enugu, Southeast, Nigeria. International Journal of Nursing and Midwifery, 2012; 3(1):6-13.

[11] Risser NL. Development of an instrument to measure satisfaction with nurses and nursing care in primary care settings. Nurs Res. 1975; 24(1):45-52.

[12] Davis J. Taking the measure of patient satisfaction. Nurse Times.1999; 95(24):52-53.

[13] Felege Hiwot referral hospital. Plan and program office annual report, 2013: 2-3

[14] Fenote Selam district hospital. Plan and program office annual report; 2013: 3-4

[15] Urden LD. Patient satisfaction measurement: current issues and implications. Outcomes Manag. 2002; $6(3): 125-131$.

[16] Mahon PY. An analysis of the concept of 'patient satisfaction' as it relates to contemporary nursing care. J Adv Nurs. 1996; 24:1241-1248.

[17] Bond S, Thomas LH. Issues in measuring outcomes of nursing. J Adv Nurs.1991; 16:1492-1502.

[18] Yellen E, Davis GC, Ricard R. The measurement of patient satisfaction. JNurs Care Qual. 2002; 16(4):23-29.

[19] Larrabee JH, Bolden LV. Defining patients' perceived quality of nursing care. J Nurs Care Qual. 2001; 16(1):34-60.

[20] Sitzia J, Wood N. Patient satisfaction: a review of issues and concepts. Soc Sci Med. 1997;45(12):1829-1843.

[21] Ventura MR, Fox RN, Corley MC, Mercurio SM. A patient satisfaction measure as a criterion to evaluate primary nursing. Nurs Res. 1982; 31(4):226-230.

[22] Uzun O. Patient satisfaction with nursing care at a University Hospital in Turkey. J Nurs Care Qual. 2001; 16(1):24-33.

[23] French K. Methodological considerations in hospital patient opinionsurveys. Int J Nurs Stud, 1981; 18:7-32.

[24] Johanesson P, Oleni M, Fridlund B. Patient satisfaction with nursing care in the context of health care: a literature study. Scand J Caring Sci. 2002; 16:337-344.

[25] Miller-Bader MM. Nursing care behaviors that predict patient satisfaction. J Nurs Qual Assur. 1988; 2:11-17. 